\title{
Artigo
}

\section{Tendências e desafios para a agenda da saúde global sob a era Trump}

\author{
Trends and challenges for the global health agenda under the Trump era
}

Maíra da Silva Fedatto ${ }^{1}$

\section{Resumo}

A agenda de Saúde Global foi/será impactada pela vitória de Donald Trump, em âmbitos doméstico e internacional. Internamente, além de freiar o Obamacare, suas posiçóes conservadoras sobre o combate ao HIV, ao abuso de opiaceos, à saúde reprodutiva das mulheres e à oneração dos serviços públicos de saúde por imigrantes irregulares, são deveras preocupantes. Na arena internacional, apesar de ter declarado que seguirá apoiando programas como o PEPFAR (President's Emergency Plan for AIDS Relief), há expectativas de cortes de até $40 \%$ nas contribuiçóes para as Organizaçóes Internacionais. O artigo visa refletir sobre a substituição do Obamacare e, no âmbito internacional, sobre a questão do aborto à luz da Regra da Mordaça Global (Global Gag Rule) e sobre o anunciado corte orçamental às organizaçôes internacionais e as possiveis consequências para a OMS, cujo orçamento depende em aproximadamente 16\% dos Estados Unidos.

Palavras-chave: Saúde; Trump; Estados Unidos; Organização Mundial da Saúde

\begin{abstract}
The Global Health agenda was / will be impacted by the victory of Donald Trump in domestic and international settings. Internally, in addition to curbing Obamacare, its conservative positions on combating HIV, opiate abuse, women's reproductive health, and burdening public health services with irregular immigrants are troubling. In the international arena, despite having stated that it will continue to support programs such as the President's Emergency Plan for AIDS Relief (PEPFAR), there are expectations of cuts of up to $40 \%$ in contributions to International Organizations. The article aims to reflect on the replacement of Obamacare and, at the international level, on the issue of abortion in the light of the Global Gag Rule and the announced budget cut to international organizations and the possible consequences for WHO. depends approximately 16\% of the United States.
\end{abstract} Key words: Health; Trump; U.S; World Health Organization.

1. Doutoranda em Relaçóes Internacionais do Joint Degree Program “King’s College London - Instituto de Relações Internacionais - USP”. Bolsista FAPESP. Jornalista pela Pontifícia Universidade Católica do Rio Grande do Sul (PUCRS), Mestre em Política Internacional e Comparada pelo Instituto de Relaçóes Internacionais da Universidade de Brasília (UnB). Pesquisadora do Núcleo de Estudos e Análises Internacionais (NEAI) do Instituto de Políticas Públicas e Relaçóes Internacionais IPPRI/UNESP. ORCID: 0000-0002-2741-7231. 
"The tree ofliberty must be refreshed from time to time with the blood of patriots and tyrants" (JEFFERSON, 1787).

\section{Introdução}

Partindo da supracitada afirmação de Thomas Jefferson e amparando-se na obra Diplomacia de Henry Kissinger (1994), acredita-se ser possível assegurar que tanto a identidade coletiva quanto a política externa norte-americana foram historicamente amparadas em duas crenças: a primeira de que ao mesmo tempo em que internamente a democracia é consolidada, os Estados Unidos devem agir como guia dos outros países; a segunda de que "os valores americanos impóe à América uma obrigação de cruzada por todo o mundo" (KISSINGER, 1994, p. 11).

Nesta direção, porém, com um olhar crítico, Pecequilo (2003) afirma que esta "crença” nos Estados Unidos como o propagador da democracia e da liberdade tem raízes anteriores à sua hegemonia consolidada a partir de 1945, isto é, para a autora o entendimento do poder e influência norte-americana nas açóes globais só é possível por uma análise histórica, rigorosa, com o fito de desvendar as origens de seu pensamento desde a independência, em 1776. Tal análise foge aos limites e objetivos desta reflexão. Para o momento concordamos com Bauman, (2013, p. 34) que no panorama mundial da atualidade "não está mais no poder de qualquer Estado ativo, sozinho, ainda que dotado de recursos, fortemente armado, resoluto e inflexível, defender certos valores no plano doméstico e virar as costas [...] aos que estão fora de suas fronteiras”.

De fato, o tema que ora nos ocupa, os problemas de saúde, é um exemplo real da afirmativa de Bauman, tendo em vista que, paulatinamente, se tornaram mais proeminentes nas políticas externas dos países. Fidler e Drager (2006) explicam que a transformação na relação entre saúde e política externa resultou tanto de eventos específicos quanto de tendências mais gerais na política mundial. A propagação da epidemia da AIDS, por exemplo, as doenças infecciosas emergentes e reemergentes, as controvérsias envolvendo comércio e saúde (exemplificadas pelo acordo TRIPS), dentre outros, forçaram os formuladores de política externa a lidar com questôes de saúde pública, até então consideradas assunto doméstico.

Neste sentido, na esteira da Guerra Fria,(19471991), a saúde internacional foi validada - através de uma rede de instituições multilaterais, bilaterais e filantrópicas - como uma ferramenta estratégica tanto da política externa quanto da econômica. A Organização Mundial da Saúde foi criada em 1946 para melhorar a saúde nos países em desenvolvimento através de estratégias como a promoção do direito à saúde e a lista de medicamentos essenciais. Contudo, a lógica da Segurança Internacional influenciou seus canais de afluxo. As intervençóes técnicas orientadas para doenças específicas e os esquemas administrativos financiados pelas sociedades industriais ocidentais se estenderam às áreas rurais de muitos países em desenvolvimento, em um esforço para incorporar mais pessoas e regióes a uma economia de mercado.

Neste contexto, Birn (2014) afirma que a Fundação Rockfeller (FR) - criada em 1913 - não apenas popularizou o conceito de saúde internacio$\mathrm{nal}^{2}$, mas foi a principal influência sobre a agenda, abordagens e ações do campo saúde do século XX. A autora afirma que os esforços da Fundação Rockefeller faziam parte de um novo movimento americano, chamado "filantropia científica”. Mais além, a FR definiu um modelo de cima para baixo

2. A saúde internacional é definida por Merson, Black e Mills (2012, p.17) como "a aplicação dos princípios da saúde pública aos problemas e desafios que afetam os países de baixa e média renda e ao complexo conjunto de forças globais e locais que os influenciam". 
de atuaçáo na saúde internacional com uma visão estritamente biomédica e ajudou o governo norte americano a fortalecer a estratégia de saúde internacional como política externa ao promover apoio político e popular para a saúde pública por meio da ajuda à criação de departamentos nacionais de saúde em todo mundo.

Com a queda da União Soviética,(1991), o presidente norte-americano Bill Clinton, (1993-2001), afirmou, em 1993, que os Estados Unidos eram a única superpotência do mundo e, por isso, tinham responsabilidades internacionais - observa-se aqui o discurso do papel "especial" do país no mundo. Clinton, entretanto, privilegiou as soluçóes multilaterais, preferencialmente junto com as Naçôes Unidas ou o Tratado do Atlântico Norte (OTAN).

Ao contrário de seu antecessor democrata, George W. Bush, (2001-2009), era cético quanto à relevância das Organizaçóes Internacionais para a promoção de um sistema internacional estável e democrático. Ao longo do seu governo, a exportação de democracia foi o cerne da Política de Defesa Nacional. No que tange a seara da saúde, as propostas de Bush destinaram-se a reforçar a capacidade do setor privado para expandir a cobertura de saúde e melhorar a prestação de serviços médicos aos americanos. No âmbito internacional, o presidente criou o PEPFAR (The U.S. President's Emergency Plan for AIDS Relief), considerada a maior mobilização de fundos na história contra uma doença, com um orçamento inicial de 15 milhóes de dólares. O programa, contudo, foi muito criticado por ter imposto como condição da ajuda que esta fosse prioritariamente utilizada na promoção da abstinência e fidelidade, a promoção do preservativo figurava como segundo objetivo.

Barack Obama, (2009-2017), foi um dos presidentes mais populares do país, sua aprovação ao deixar o cargo ficou atrás apenas de Bill Clinton e Ronald Reagan. Consensualmente, o ponto alto de sua administração foi a economia, especialmente a recuperaçấo dos empregos perdidos durante a crise de 2008. Para o presente artigo, porém, é central a aprovação do Affordable Care Act (ACA) - mais conhecido como Obamacare - em âmbito doméstico. No âmbito da saúde internacional, destaca-se que Obama aumentou as interaçôes diplomáticas com a OMS e avançou nos diálogos sobre as prioridades da segurança da saúde. Ademais, em 2011, a OMS e o Departamento de Saúde e Serviço Humano dos Estados Unidos assinaram um memorando de entendimento para aumentar a cooperação na preparação de desastres e pandemias, bem como vigilância, relatórios e resposta a doenças (MORRISON, 2013).

Por sua vez, Donald Trump, atual presidente norte-americano, é considerado um dos presidentes mais impopulares dos Estados Unidos. De acordo com pesquisa da CNN, publicada em agosto de 2017, sua aprovação era de 36\%. Durante a campanha presidencial - e durante seu primeiro ano na presidência - Trump fez diversas declarações polêmicas, dentre as quais a agenda de restrição aos imigrantes. O presidente afirma que os imigrantes irregulares - os quais, ele frisa obstinadamente serem predominantemente do México - custariam USD 113 bilhôes por ano aos serviços públicos americanos, incluindo hospitalização e cuidados de saúde, e acrescenta, que estes custos serão eliminados quando onze milhóes de imigrantes que vivem nos Estados Unidos forem deportados. Não obstante, fez a promessa de construir um muro na divisa com o México para conter o ingresso de imigrantes em território norte-americano e, também, recrudescer tanto o controle policial fronteiriço e doméstico como as detençôes, com deportação imediata.

As declaraçóes polêmicas aliadas a maioria no Senado traz a baila o fato de que a vitória de Donald Trump desenhou um clima de preocupação internacional. Ora se no âmbito doméstico o novo Presidente, tomando apenas o tema de nossas reflexôes, 
a saúde, anuncia "tempos sombrios" substituindo o Obamacare, o que esperar no âmbito da saúde global? O que esperar nos próximos anos em relação aos aportes financeiros significativos e fundamentais dos Estados Unidos para os organismos internacionais? O presente estudo, concordando com a literatura especializada que aponta implicaçóes substantivas tanto no âmbito doméstico norte-americano como na esfera internacional, busca responder estas e outras perguntas inserindo-se no debate das análises e contribuindo para o entendimento do cenário internacional desde as açóes, no âmbito doméstico, da nação mais poderosa do planeta.

\section{Impacto na esfera doméstica: a revogação do Obamacare.}

Primeiramente, é impossível falar sobre saúde e/nos Estados Unidos sem lembrarmos que o país é a única nação industrializada avançada sem cuidado universal de saúde. É importante destacar que - apesar de as despesas médicas serem a causa mais comum de falência pessoal no país - ao longo da corrida presidencial de 2016, a implantação de um sistema nacional de saúde não foi sequer discutida pelos representantes dos partidos.

De acordo com o Departamento de Saúde e Serviços Humanos (HHS - Department of Health and Human Services), o sistema de saúde dos Estados Unidos é "híbrido" e único entre os países industrializados avançados, tendo em vista a inexistência tanto de um sistema de saúde uniforme quanto de uma cobertura universal de cuidados de saúde. O National Health Expenditures 2014 Highlights (HHS) aponta que, em 2014, 48\% dos gastos com cuidados de saúde no país foram provenientes de fundos privados, $28 \%$ provenientes de famílias e $20 \%$ provenientes de empresas privadas. Neste sentido, o governo federal arcou com $28 \%$ dos gastos, enquanto os governos estaduais e locais representaram $17 \%$. Com efeito, a maioria dos cuidados de saúde, mesmo que seja financiada publicamente, é entregue de forma privada.

Mais além, o relatório Health at a Glance 2017 da Organização para a Cooperação e o Desenvolvimento Econômico (OCDE) aponta que apesar de, dentre os membros da Organização, os Estados Unidos serem o país cujo governo desempenha menor papel no financiamento geral dos cuidados de saúde, o gasto público em saúde per capita no país é maior do que todos os outros países da OCDE, chegando a 9.892 dólares por residente (OECD, 2017). Este valor - quando comparado com outros países do G7 - é 80\% maior que o gastado na Alemanha, e mais do que o dobro do gasto por pessoa em países como Canadá, França e México. Contudo, o país possui os piores resultados da seara da saúde. Por exemplo: menor expectativa de vida $^{3}$, maior mortalidade infantil e maior obesidade em relação à grande parte dos países desenvolvidos como Austrália, Canadá, Reino Unido, Alemanha, França e Japão.

Ainda de acordo com o relatório da OCDE (ver tabela abaixo), a maioria dos países da OCDE alcançou uma cobertura universal (ou quase universal) dos custos de cuidados de saúde para um conjunto básico de serviços, que geralmente incluem consultas com médicos e especialistas, testes e exames e procedimentos cirúrgicos e terapêuticos. Nos Estados Unidos, no entanto, apenas 35.6\% da população tem cobertura total e $55.3 \%$ tem cobertura privada de saúde primária.

Existem no país alguns programas financiados pelo governo, como o Medicare - destinado a pessoas com mais de 65 anos - ou o Medicaid, para pessoas de baixa renda. Veteranos das Forças Armadas são cobertos por um programa do governo,

3. De acordo com o relatório da OECD, a expectativa de vida dos Estados Unidos em 2015 era de 78.8 anos, enquanto da Austrália 82.5; Canadá 81.7; Reino Unido 81; Alemanha 80.7; França 82.4; e Japão 83.9. 
Tabela 1 - Custos de cuidado a saúde Cobertura populacional para um conjunto essencial de serviços, 2015 (ou ono mois próximo)

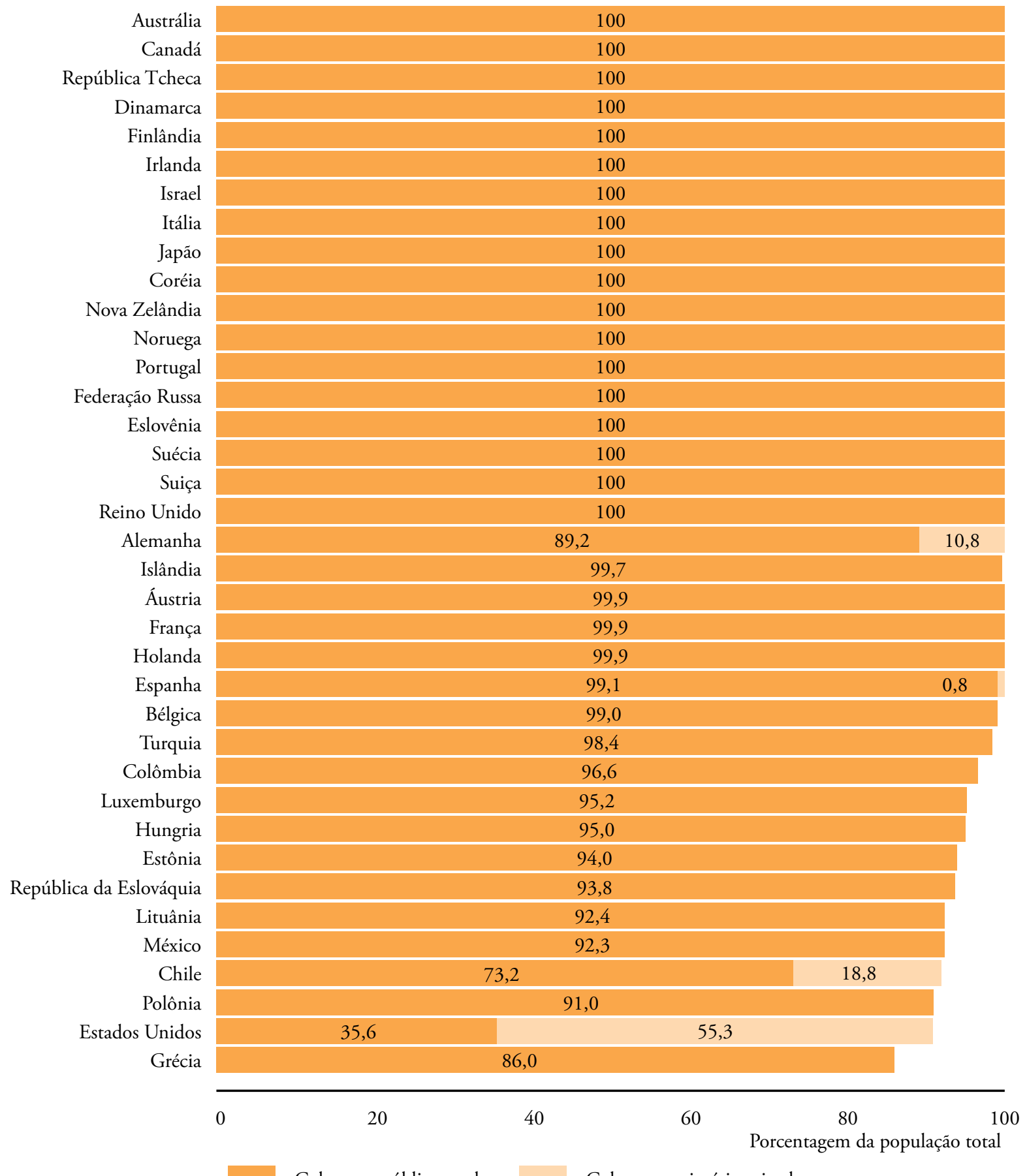

Cobertura pública total

Cobertura primária privada

Fonte: Organização para a Cooperação e o Desenvolvimento Econômico (OCDE) (2017).

assim como crianças de famílias pobres que não se enquadram nas exigências do Medicaid. Contudo, a maioria dos americanos precisa adquirir seu próprio plano de saúde, seja por meio de seus empregadores ou por conta própria. No caso dos planos de saúde privados, há variaçóes nas regras e nos valores a serem pagos.

Criado pelo presidente Barack Obama, o Affordable Care Act (ACA) - comumente conhecido como Obamacare - é considerado a maior mudança 
na política norte americana de cuidados de saúde desde a década de 1960 (Manchikati et al, 2017) e se refere especificamente a duas leis: Patient Protection and Affordable Care Act (PL 111-148) e a Health Care and Education Reconciliation Act of 2010 (PL 111-152). Sendo, essencialmente, uma lei regulamentatória federal que amplia a autoridade do governo federal para regular a indústria de seguro de saúde e para exigir que a população obtenha - e que as grandes empresas ofereçam - seguro de saúde sob pena de pagarem multas. Os objetivos principais do ACA eram: aumentar o número de segurados, melhorar a qualidade dos cuidados e reduzir os custos dos cuidados de saúde. Um ponto que muitas vezes perdeu na discussão é a distinção entre acessibilidade e acesso.

Neste sentido, a reforma da cobertura de saúde, que entrou em vigor em Janeiro de 2014, obriga as seguradoras a cobrirem alguns benefícios essenciais como: tratamento para a saúde mental e internamentos (incluindo emergências), além de reembolsarem integralmente cuidados preventivos, como exames de diabetes, vacinas ou métodos contraceptivos. A lei proíbe, ainda, as seguradoras de variarem os valores dos planos com base no histórico clínico ou no sexo, de se recusarem a assegurar um paciente muito caro, ou de limitarem a quantidade de reembolsos anuais - práticas que eram consideradas legais e que levaram alguns pacientes com doenças graves à ruína financeira. Em troca, exige-se que qualquer pessoa residente nos Estados Unidos, americana ou estrangeira, contrate um plano de saúde. A multa para a não contratação seria de US\$ 95 em 2014 e, posteriormente, subiria para US\$ 695 (LANFORD; QUADAGNO, 2015).

Assim, desde janeiro de 2014, quase todos os americanos precisavam ter algum tipo de seguro de saúde de seu empregador, um plano individual ou através de um programa público como Medicaid ou Medicare. De acordo com a ONG Kaiser
Family Foundation (KFF), desde que o "mandato individual" entrou em vigor, o número total de adultos não segurados caiu de 41 milhóes em 2013 para 32,3 milhóes em 2014. Com efeito, os maiores ganhos de cobertura concentraram-se entre pessoas de baixa renda, pessoas de cor e jovens adultos (KFF, 2016). Contudo, Manchikanti (2017, p.1) argumentam que, apesar de ter aumentado grandemente o número de segurados, pouco se fala sobre as seis milhóes de pessoas que perderam seu seguro. Os autores afirmam, ainda, que pelo fato de a expansão ter sido baseada na expansão do Medicaid, conseqüentemente, o ACA não funcionou bem para a classe média, particularmente aqueles que ganham mais de $400 \%$ do nível de pobreza federal, que constitui $40 \%$ da população e não recebe ajuda.

É importante destacar que os debates sobre a reforma da saúde ocorreram - e continuam ocorrendo - em um ambiente político conturbado e altamente. O Congresso aprovou o ACA sem votos republicanos na Câmara ou no Senado. Nesta direção, ao longo da campanha presidencial, Donald Trump criticou impetuosamente o Obamacare, chamando-o de "catástrofe" e "máquina de destruir empregos", e afirmou que iria revogá-lo assim que chegasse à Casa Branca. Contudo, a alternativa para o setor da saúde nunca esteve clara nos discursos do novo presidente.

Em linhas gerais, o chamado Trumpcare propóe acabar com a obrigatoriedade do contrato individual de um seguro de saúde, incluir subsídios federais baseados na idade e não na renda, deduzir o custo total dos prêmios de seguro de saúde das declaraçôes fiscais federais, permitir compras de medicamentos prescritos em países estrangeiros a fim de reduzir os custos de atendimento.

Em consonância com seu discurso, a primeira Ordem Executiva - assinada horas após a posse - determinava uma minimização do peso or- 
çamentário do Afordable Care Act enquanto não fosse revogado completamente. Porém, se por anos a oposiçấo à reforma da saúde de Obama uniu o Partido Republicano, paradoxalmente, acabou por dividi-lo. A imprensa norte-americana apontava que a pauta da saúde - mais especificamente as questôes combinadas do ACA, Medicare e Medicaid - romperia a coalizão republicana, tendo em vista dissensos nos bastidores do Partido.

Se por um lado os conservadores ortodoxos, especialmente a Freedom Caucus, defendiam que a lei de Obama deveria ser completamente abandonada em favor de um sistema que eliminasse subsídios e devolvesse aos indivíduos e ao mercado a iniciativa de organizar fundos mútuos e seguros com coberturas variadas de acordo com os interesses e possibilidades de cada um, os parlamentares republicanos moderados passaram a temer as consequências de uma reforma - que, de acordo com estimativas, deixaria 22 milhóes de americanos sem cobertura de saúde - logo antes das eleições de 2018 para o Congresso. Preocupação que estava em consonância com uma pesquisa nacional, de março de 2017, que apontava que apenas $17 \%$ dos americanos apoiavam a mudança pretendida por Trump, enquanto 56\% se opunham e $26 \%$ eram indecisos. Mesmo entre os eleitores republicanos, o apoio não ultrapassou $24 \%$.

Apesar de ter sua proposta para a área da saúde inicialmente retirada de pauta, no final de Março, após não conseguir os votos necessários dentro do Partido Republicano para aprová-la, Trump obteve vitória importante na Câmara dos Estados Unidos, em maio. Foi aprovado - por 217 votos contra 213, sendo que 20 republicanos votaram contra -, na câmara baixa do Congresso, o projeto "Lei Americana de Cuidados de Saúde" (The American Health Care Act - AHCA), que prega menos intervenção do Estado e mais autonomia para os 50 estados norte-americanos.

De acordo com o Congressional Budget Office (agência apartidária ligada ao Congresso), caso a lei fosse aprovada no Senado, 51 milhões de cidadãos americanos deverão ficar sem nenhuma cobertura de seguro ao longo da próxima década, 23 milhôes a mais do que se fosse mantido o Obamacare (2009-2017). O relatório chama atenção também para a estimativa de que a redução do déficit americano na próxima década devido ao Trumpcare seja $50 \%$ menor do que a prometida quando o projeto foi apresentado pelos republicanos (US\$ 119 bilhões ao invés de US\$ 337 bilhôes) (CBO, 2017). Contudo, no final de julho, a última alternativa da liderança republicana no Senado e da administração de Trump para revogar o Obamacare falhou com a ajuda do voto de três senadores republicanos conservadores. Derrota que havia sido conjecturada por John McDonough, professor de Saúde Pública de Harvard. De acordo com McDonough, como vem sendo observado, muitos republicanos apreciam algumas disposiçóes não controversas do Obamacare - tais como a exigência de que as companhias de seguros não neguem cobertura para pessoas com condiçóes médicas pré-existentes ou que as jovens até 26 anos possam ser abrangidos pelo plano de saúde da família.

Diante do exposto, pode-se concluir que a tentativa de desmantelar o ACA é sintomática do primeiro ano da presidência de Trump - não somente em âmbito doméstico, mas internacional, como será analisado nos próximos itens- marcado por recuos, desvios, dificuldades, poucas vitórias expressivas e derrotas bastante claras.

\section{Ordem interna, impacto internacional: a questão do aborto.}

O direito constitucional ao aborto nos Estados Unidos data de 1973, contudo, alguns "limites" foram impostos a esse direito, fundamentados no interesse estatal em proteger a saúde da mulher e 
a potencial vida do feto. Estabeleceu-se o "modelo de trimestres", segundo o qual: durante o primeiro trimestre o Estado náo poderia interferir no direito da mulher de decidir terminar a gravidez; durante o segundo trimestre, o Estado poderia regulamentar o procedimento, mas apenas naquilo que razoavelmente se conectasse com a preservação da saúde feminina; e, durante o terceiro trimestre, quando o feto passaria a ser viável fora do útero, o Estado poderia inclusive proibir o aborto (UNITED STATES SUPREME COURT,1973).

Quase vinte anos depois, quando o tema voltou ao tribunal, encontrou não apenas a realidade das práticas médicas significativamente transformadas devido aos desenvolvimentos científicos, mas também uma corte cuja composição foi profundamente afetada pela "era Reagan", quando o aborto se tornou um dos focos de polarização política no país. Apesar de dividido, o tribunal reafirmou o direito de acesso ao aborto e o fim do "modelo de trimestres". Ou seja, permitiu a regulação do aborto durante toda a gravidez, mas estabeleceu que "como em qualquer procedimento médico, o Estado pode estabelecer regulamentaçóes para promover a saúde e segurança da mulher procurando um aborto, mas não pode impor regulamentações sanitárias desnecessárias que tragam um obstáculo substancial para a mulher" (UNITED STATES SUPREME COURT,1992).

Com isso, a Suprema Corte - e o judiciário americano como um todo - entrou no debate sobre a regulamentação do aborto pelo Estado ao mesmo tempo em que opositores passaram a evocar motivos morais para utilizar regulamentações médicas a fim de dificultar o acesso.

Diante deste cenário, a ascensão de Donald Trump torna o aborto um tema que gera preocupações, tendo em vista suas posiçóes conservadoras e a consistente oposição de seu vice, Mike Pence, a qualquer medida que melhore o acesso ao abor- to. Em janeiro de 2017, por exemplo, Pence foi o primeiro vice-presidente americano a participar $\mathrm{da}$ "Marcha pela Vida", manifestação anual dos que se opõem à interrupção voluntária da gravidez. Mais além, 4 dias após a posse, Trump assinou sua $3^{\text {a }} \mathrm{Or}$ dem Executiva: a proibição de dinheiro federal para grupos internacionais que executem ou forneçam informaçôes sobre abortos.

Elucida-se, primeiramente, que esta ordem não se constitui como um passo em direção à proibição do aborto nos Estados Unidos, contudo, é relevante fora das fronteiras do país. Para compreendermos o significado e, consequentemente, o impacto desta Ordem Executiva para a Saúde Global, faremos uma breve visita histórica sobre o tema.

A questão do aborto divide republicanos e democratas há décadas. Em 1984, o presidente republicano Ronald Reagan interrompeu o financiamento de grupos internacionais que realizavam ou forneciam informaçóes sobre aborto ao promulgar a Política da Cidade do México, que ficou amplamente conhecida como Global Gag Rule (Regra da Mordaça Global). Estabelecia-se que Organizaçóes não Governamentais estrangeiras que recebessem assistência de saúde dos Estados Unidos não utilizassem seus próprios fundos (e não somente os fundos norte-americanos) para: 1 . Oferecer serviços de aborto; 2. Aconselhar os pacientes sobre a opção do aborto ou encaminhá-los para o aborto; 3. Advogar pela liberalizaçẫo das leis do aborto (GEZINSKI, 2012).

A implementação da Global Gag Rule limitou todas as discussōes sobre planejamento familiar, incluindo o uso de preservativos para prevenir a infecção pelo HIV e o espaçamento de gravidez de vários anos para evitar mortes maternas. Como consequência, diversas organizaçóes como a Organização Mundial da Saúde, o Fundo das Nações Unidas para a População e a Family Health International perderam milhóes de dólares em apoio do governo dos EUA durante os anos em que a regra da mordaça foi aplicada. 
Em 2006, o Escritório Geral de Transparência do Congresso (Congressional General Accountability Office) concluiu que a lei da mordaça, aliada a política de promover a abstenção de sexo, estava prejudicando a luta global contra a epidemia da AIDS. Em 2011, pesquisadores da Universidade de Stanford publicaram evidências empíricas - através de uma amostra com 20 países pobres que recebiam assistência externa dos Estados Unidos entre 1994 e 2008 - que apontavam que a Política da Cidade do México estava associada ao aumento das taxas de aborto nos países da África Subsaariana devido à perda de financiamento para os grupos náo Governamentais que promoviam contracepção.

No Kenya, por exemplo, a organização Marie Stopes International Kenya (MSI Kenya) que recusou os termos da GGR, em 2001, perdeu significativamente os fundos de planejamento familiar dos EUA e teve que fechar duas clínicas. As clínicas da MSI prestam serviços críticos a populaçóes pobres e desatendidas em áreas urbanas, periurbanas e rurais; esses serviços incluíam: planejamento familiar (incluindo a provisão de contracepção de emergência), aconselhamento e teste voluntário (VCT) para HIV/AIDS, manejo de infecçóes sexualmente transmissíveis, serviços farmacêuticos, serviços laboratoriais, cuidados pós-aborto, serviços de saúde materno-infantil, exames de papanicolaou, dentre outros. Após o fechamento dessas - e de outras clínicas em 2005, pelo menos 9.000 pessoas - principalmente mulheres e crianças - ficaram com pouco ou nenhum acesso aos cuidados de saúde. Os democratas revogaram a lei sob o governo Clinton (1993-2001), que foi reintegrada quando George W. Bush assumiu em 2001 e voltou a ser derrubada pelo presidente Barack Obama em 2009.

Após a Ordem Executiva de Trump, a Holanda anunciou o lançamento de um fundo global para ajudar mulheres a terem acesso a serviços de aborto, afirmando que o decreto de Trump irá provocar uma escassez de financiamento de milhóes de dólares nos próximos anos. Suécia, Dinamarca, Bélgica, Luxemburgo, Finlândia, Canadá e Cabo Verde decidiram apoiar a açấo holandesa. A vice-primeira-ministra da Suécia, Isabella Lovin alerta para "as consequências (muito sérias) para os objetivos globais de igualdade de gênero e erradicação da pobreza”.

Concretamente, a regra da mordaça global, sob o governo de Bush, teve um impacto direto de aproximadamente US\$ 600 milhōes em programas da USAID, com repercussão no PEPFAR e nos Centros de Controle e Prevençáo de Doenças (CDC). Sob Trump, vislumbra-se um horizonte mais "escuro", pois, estima-se que as restrições podem chegar a 8,8 bilhóes em programas de saúde e de desenvolvimento. Dependendo de sua interpretação legal, impor até mesmo limitaçóes à ajuda humanitária, esforços de assistência alimentar e programas de saneamento e higiene.

Explica-se este impacto tendo em vista que os Estados Unidos, isoladamente, se destacam como o maior doador a esforços globais na área da saúde, oferecendo quase 3 bilhóes de dólares por ano por meio da Agência pelo Desenvolvimento Internacional (USAid).

\section{A organização mundial da saúde e a agenda da saúde global}

Desde a década de 1990, a Organização Mundial da Saúde enfrenta inúmeros desafios e limitações, tanto de financiamento quanto de liderança, tendo em vista a crescente e expressiva atuação de outros organismos internacionais e entidades privadas, inclusive as filantrópicas.

A OMS possui duas fontes primárias de receita: as contribuiçóes fixas dos Estados-Membros, escalados por renda e população; e as contribui- 
çóes voluntárias, que são fornecidas pelos Estados-Membros, organizaçóes privadas e indivíduos. Atualmente, $80 \%$ de seu financiamento derivam de contribuições voluntárias.

Os Estados Unidos são o maior contribuinte da OMS e, durante muitos anos, forneceram 22\% de todas as contribuiçóes dos Estados-Membros, a taxa máxima permitida. Entre 2010 e 2016, a contribuição do país foi bastante estável, variando entre 93 milhóes e 114 milhões de dólares. Por outro lado, as contribuiçóes voluntárias para projetos específicos variaram de acordo com as mudanças nas prioridades do governo. Por exemplo, nos últimos anos, as contribuições voluntárias foram maiores em 2015 (US\$ 324 milhóes), refletindo o apoio para a resposta à epidemia de Ebola na África Ocidental.

Em outubro de 2016, a Diretora-Geral da OMS, Margaret Chan, fez um apelo de financiamento aos doadores e representantes dos países. A reuniáo contou com a participação de setenta e dois Estados-Membros e vinte organizaçôes internacionais, e teve como objetivo levantar fundos para fechar a brecha orçamentária de US\$ 500 milhóes da agência e financiar novas reservas de emergência para combater focos e resolver crises humanitárias.

Diante deste cenário, são passíveis de preocupaçáo os dois projetos de ordem executiva que visam reduzir radicalmente o apoio norte-americano às Naçóes Unidas. A ordem "Auditoria e Redução de Financiamento dos EUA de Organizaçóes Internacionais» visa reduzir $40 \%$ do apoio financeiro para as agências das Nações Unidas, além de iniciar um processo de auditoria visando desenterrar a corrupção ou a má administração dos fundos dentro do sistema, permitindo ainda mais cortes.

Destacamos que grande parte da mídia norte-americana alertava - ainda durante a campanha presidencial - que Trump não é um grande "fâ" de programas de assistência/ajuda externa. Para ilustrarmos essa afirmação, vale lembrar que, durante a epidemia do Ebola em 2014, Trump se opôs à volta, aos Estados Unidos, dos trabalhadores da saúde norte americanos que estavam na Libéria e na Serra Leoa. $\mathrm{Na}$ época, o atual presidente escreveu em seu Twitter (em letras garrafais): "Keep them out of here".

Cabe refletir, no entanto, que o argumento de Donald Trump de que o crítico orçamento não seria capaz de "manter os americanos seguros", configura-se como uma estratégia míope ao não reconhecer o papel crucial que o desenvolvimento desempenha no enfrentamento de desafios complexos da segurança global.

A imprensa americana - destacando-se a CNN e o New York Times - apontam que os cortes propostos pelo governo Trump ajudariam a compensar cerca de US\$ 54 bilhóes em gastos militares adicionais. Porém, o soft power da assistência ao desenvolvimento dos Estados Unidos, trabalho realizado pela Agência dos Estados Unidos para o Desenvolvimento Internacional (USAID) e outros, deve ser reconhecido como um ativo estratégico que não é menos poderoso do que os militares para enfrentar os atuais desafios multifacetados. E por uma fraçáo do custo - menos de um por cento do orçamento federal total.

Em fevereiro de 2017, mais de 120 líderes militares aposentados enviaram uma carta ao Congresso onde ressaltaram sua "forte convicção de que elevar e fortalecer a diplomacia e o desenvolvimento são fundamentais para manter a América segura". Eles reconheceram a complexidade das crises no mundo do século XXI, e afirmaram que esses problemas "não têm soluções militares sozinhos".

Neste sentido, vale lembrar que apesar do exército norte-americano ter liderado a campanha contra o Estado Islâmico, é a USAID, juntamente com a ONU e outros parceiros internacionais, que desempenha um papel fundamental na estabilização de áreas liberadas, além de fornecer assistência 
humanitária e assegurar o acesso a serviços essenciais como água, eletricidade e cuidados de saúde. Assim, uma estabilização bem-sucedida dessas áreas ajuda a evitar o surgimento de perigosos vazios de poder que podem levar a novos conflitos.

Não obstante, outras Ordens Executivas e Memorandos Presidenciais de Segurança Nacional (do inglês National Security Presidential Memoranda - NSPMs) poderáo impactar a saúde tanto na esfera interna quanto internacional.

Por último, cabe destacar que na intitulada "Ordem Executiva: protegendo a nação da entrada de terroristas estrangeiros nos Estados Unidos", Trump cita uma lei de imigração de 1952 que dá ao presidente a capacidade de suspender a entrada nos Estados Unidos "de todos os estrangeiros ou de qualquer classe de estrangeiros" quando entender "prejudicial aos interesses" do país. Em 1965, no entanto, uma revisão da lei afirma que os indivíduos não podem ser "discriminados na emissão de um visto de imigrante" por causa de sua "raça, sexo, nacionalidade, local de nascimento ou local de residência”.

A Ordem Executiva contra imigrantes provocou - além de uma onda de protestos e de açôes judiciais contra a Casa Branca - a indignação da comunidade médica norte-americana. Os imigrantes representam uma fatia significativa da força de trabalho na área da saúde, que inclui quase 17\% dos 12,4 milhóes de pessoas nos Estados Unidos trabalhando como médicos, enfermeiros, dentistas e outras ocupaçóes de saúde em 2015 (MIGRATION POLICY INSTITUTE, 2017).

Os trabalhadores de saúde estrangeiros são admitidos nos Estados Unidos sob uma variedade de categorias temporárias e permanentes de vistos, incluindo o H-1B. Assim, apesar do foco da Ordem Executiva ser o veto migratório a seis países, uma potencial limitação do visto H-1B e outros vistos profissionais poderia levar à escassez de pessoal médico em todo o país. Neste sentido, em uma carta aberta ao secretário de Segurança Interna, John F. Kelly, o diretor-presidente da American Medical Association, Dr. James L. Madara, afirmou que é "vitalmente importante" que esse processo não impeça o acesso dos pacientes a tratamento oportuno ou restrinja os médicos e graduados de medicina estrangeiros aos quais foram concedidos vistos para treinar, praticar ou participar de conferências médicas nos EUA.

\section{Considerações fincis}

É inegável que os desafios no campo da saúde não podem ser contidos nas fronteiras nacionais, assim, é fundamental compreendê-los como problemas comuns que demandam esforços coletivos. É imperativo, portanto, o estabelecimento de uma agenda compartilhada e de objetivos definidos tanto no campo acadêmico como na prática institucional - do tema da saúde na agenda de pesquisa da área de Relaçóes Internacionais.

Desde antes de sua posse, em 20 de janeiro de 2017, e depois, como presidente dos Estados Unidos, Donald Trump emitiu diversas declaraçóes, ordens executivas e memorandos, com potencial e preocupante influência sobre assuntos domésticos e internacionais, e sobre a agenda de soft power norte americana. Se, por um lado, Trump já afirmou que os Estados Unidos seguiriam liderando a luta contra a epidemia da AIDS, também já condicionou a concessão de alguma ajuda ao tipo de relacionamento que o país tiver com os Estados Unidos.

Diante do cenário exposto, conclui-se que a Era Trump pode alterar profundamente a agenda da saúde global. Os Estados Unidos configuram-se como os maiores doadores de fundos para a área. Um investimento que investia eficientemente na liderança global americana, além de promover o crescimento econômico e salvar milhóes de vidas por apenas $0,25 \%$ do orçamento do país. 
Contudo, o presidente norte americano vem sendo - e provavelmente continuará - desafiado pelos parceiros mais próximos dos Estados Unidos, como o Canadá, o Japão, o Reino Unido e a Alemanha, para - dentre outros - incentivar o sistema multilateral de saúde e desenvolvimento.

\section{Referênciass}

AMERICAN MEDICAL ASSOCIATION - AMA. Urges Trump Administration to Clarify Immigration Executive Order. Disponível em: https://www.amaassn.org/ama-urges-trump-administration-clarify-immigration-executive-order. Acesso em 19 de março de 2017.

BAUMAN, Z. Danos colaterais: desigualdades sociais numa era global. Rio de Janeiro: Zahar, 2013.

BENDAVID Eran ; AVILA Patrick ; MILLER Grant. United States aid policy and induced abortion in sub-Saharan Africa. World Health Organization, Genebra, 27 set. 2011. Disponível em: http://www.who.int/bulletin/volumes/89/12/11-091660/en/ Acesso em: 19 mar. 2018.

BIRN Anne-Emanuelle. Philanthrocapitalism, past and present: The Rockefeller Foundation, the Gates Foundation, and the setting(s) of the international/global health agenda. Toronto, v.12, n.1, nov. 2014, Disponível em: < http:// www.hypothesisjournal.com/?p=2503\#sthash.jgB8lCCt.dpuf > Acesso em: 19 mar. 2018.

ESTEPA Jéssica. Here are some of the 435 times Trump criticized Obamacare on Twitter, USA Today, Virginia, 7 mar. 2017. Disponível em: <https://www.usatoday.com/story/ news/politics/onpolitics/2017/03/24/here-are-some-of-the-435-times-trump-criticized-obamacare/99595246/ >Acesso em : 19 mar. 2018.

FIDLER, David; DRAGER, Nick. Health and foreign policy. Bulletin of the World Health Organization, Genebra, vol 84, 2006, Disponível em:< http://www.who.int/bulletin/volumes/84/9/06-035469/en/> Acesso em: 19 mar. 2018.

FELDSCHER Karen. The future of public health under President Trump, Havard T.H Chan, 15 nov. 2016. Disponível em:< https://www.hsph.harvard.edu/news/features/the-future-of-public-health-under-president-trump/. Acesso em: 19 mar. 2018.

GARRETT, Laurie. Trump: two weeks. Council on Foreign Relations, New York, 3 fev. 2017. Disponível em: <https:// www.cfr.org/about/newsletters/archive/newsletter/n4290 Acesso em: 19 mar. 2018.

JONES, David K.; BRADLEY, Katharine; OBERLANDER, Jonathan. Pascal's Wager: Health Insurance Exchanges, Obamacare, and the Republican Dilemma. Journal of Health Politics, Policy and Law, Volume 39, N. 1: p.97-137. 2014. KISSINGER, Henry. Diplomacy. Pocket, 1994.
MAJEROL, Melissa; KEWKIRK, Vann; GARFIELD, Rachel. The Uninsured: A Primer - Key Facts About Health Insurance and The Uninsured in the Era of Health Reform, Kaiser Family Foundation, California, $10 \mathrm{dez}$. 2017. Disponível em: <http://kff.org/uninsured/report/the-uninsured-a-primer-key-facts-about-health-insurance-and-the-uninsured-in-the-era-of-health-reform > Acesso em: 19 mar. 2018.

MALLOY Tim ; SMITH Patt. U.S voters oppose gop health plan 3-1, quinnipiac university national poll finds; big opposition to cuts to medicaid, planned parenthood. Quinnipiac University Polling Institute, Connecticut ,2017.

MANCHIKANTI, Laxmaiah; HELM, Standiford; BENYAMIN, Ramsin; HIRSCH, Joshua. A Critical Analysis of Obamacare: Affordable Care or Insurance for Many and Coverage for few? Health Policy Review in Pain Physician Journal. Kentucky, 2017. p.111-148.

MERSON MH, BLACK RE, MILLS AJ. International public health: diseases, programs, systems, and policies. Third Edition Jones And Bartlett Learning Publishers; 2012.

MCDONOUGH, John. Entrevista. The future of public health under President Trump. Harvard T.H. Chan. School of Public Health. Disponível em: <https://www.hsph.harvard. edu/news/features/the-future-of-public-health-under-president-trump/ .> Acesso em 17/04/2017.

MCKEE, Martin; GREER, Scott L.; STUCKLER, David. What will Donald Trump's presidency mean for health? A scorecard. The Lancet, vol. 389, n. 10070, 18 fev. 2017. p 748-754.

ALTORJAI Szilvia; BATALOVA Jeanne. Immigrant HealthCare Workers in the United States, Migration Policy Institute, Washington, 28 jun. 2017. Disponível em:< http://www. migrationpolicy.org/article/immigrant-health-care-workers-united-states >Acesso em: 19 mar. 2018.

NATIONAL HEALTH EXPENDITURES HIGHLIGHTS, Center for Medicare and Medicaid Services, Baltimore, 1 ago .2017. Disponível em:< https://www.cms.gov/research-statistics-data-and-systems/statistics-trends-and-reports/ nationalhealthexpenddata/nationalhealthaccountshistorical. html>Acesso em: 19 mar. 2018.

ORGANISATION FOR ECONOMIC CO-OPERATION AND DEVELOPMEN. Health at a Glance 2017: OECD Indicators, OECD Publishing, Paris.2017.

OVER 120 retired generals, admirals on state and usaid budget: "now is not the time to retreat. U.S Global Lidership Coalition, Washington, 7 fev. 2017. Disponível em: http:// www.usglc.org/newsroom/over-120-retired-generals-admiralson-state-and-usaid-budget-now-is-not-the-time-to-retreat/ Acesso em: 19 mar. 2018.

PECEQUILO, Cristina Soreanu. A Política Externa dos Estados Unidos: continuidade ou mudança? Editora UFRGS. Porto Alegre, 2003. 
58 - Conjuntura Internacional - Belo Horizonte, ISSN 1809-6182, v.14 n.3, p.46 - 58, jun. 2018

UNITED STATES OF AMERICA, PUBLIC LAW 111-

148, March 23, 2010. Disponível em: <https://www.congress. gov/111/plaws/publ148/PLAW-111publ148.pdf >. Acesso en:19 mar.2018

UNITED STATES OF AMERICA, PUBLIC LAW 111152. March 30, 2010. Disponível em: <https://www.gpo.gov/ fdsys/pkg/PLAW-111publ152/pdf/PLAW-111publ152.pdf > .Acesso em: 19 mar.2018

UNITED STATES SUPREME COURT. ROE v. WADE, Texas, 22 jan. 1973. Disponível em:< http://caselaw.findlaw.com/ us-supreme-court/410/113.html.>Acesso em: 19 mar. 2018. 